\title{
Experimental Investigation of Natural Fiber Reinforced Polymers
}

\author{
Irene S. Fahim, Salah M. Elhaggar, Hatem Elayat
}

Department of Mechanical Engineering, The American University in Cairo, Cairo, Egypt.

Email: \{ico4000, elhaggar, helayat\}@aucegypt.edu

Received November $21^{\text {st }}, 2011$; revised December $31^{\text {st }}, 2011$; accepted January $10^{\text {th }}, 2012$

\begin{abstract}
The potential usage of virgin Low density polyethelyne (LDPE) reinforced with different concentrations ( $2 \%, 5 \%$ and $6 \%$ by weight) of treated rice straw with different lengths $(2 \mathrm{~mm}, 4 \mathrm{~mm}$ and $6 \mathrm{~mm})$ is investigated to produce high value products that have technical and environmental demand. The two treatment methods used for rice straw are alkali and acidic treatments of rice straw. The removal of impurities and waxy substances from fiber surface avoid creation of rougher topography after treatment and improves the quality of fiber, also content of hemi cellulose and lignin decrease so increase effectiveness of fiber due to dispersing of fiber in matrix. The reinforcing material is embedded in the matrix material to enhance tensile and flexural behaviors of the synthesized composite. The result of investigating these two mechanical properties, using statistical analysis \& design of experiments, showed an enhancement in the mechanical properties of the virgin polymer composite compared to the virgin polymer. The flexural stress of the composite increased three times the virgin flexural stress, while the tensile stress increased eight times the original tensile stress.
\end{abstract}

Keywords: Polymers-Matrix Composites (PMCs); Fiber Reinforced Plastic (FRP); Natural Fibers; Low Density Polyethylene (LDPE)

\section{Introduction}

Research interest has been shifting from monolithic materials to fiber reinforced polymeric materials. Composite material is made of the combination of two different materials to achieve certain properties different from each material on its own. One of the two materials acts as a matrix, while the other acts as reinforcing material. The reinforcing material is imbedded in the matrix material to improve its mechanical and physical properties. Mechanical properties of composites vary according to the matrix and reinforced materials used. The natural fiber reinforced composite have low maintenance requirements, high stress to weight ratio, high corrosion, impact resistance, non conductive, avoid electrical hazards, reduced cost, easy installation due to light weight and fire retardant. These composites are used in aerospace industry (tails, wings, propellers), bicycle frames, boat hulls, fishing rods, storage tanks, baseball bats, ice skating boards, door panels, automobile industry, construction material for buildings, marine application and sporting goods industry [1]. The reinforcing material is rice straw. It is hollow cellulose fibers held together by a lignin and hemicelluloses. Each fibril consists of a thin primary wall around a thick secondary wall. The secondary wall is made up of three layers and a thick middle layer. This layer determines the mechanical properties of the fiber. The middle layer consists of a series of helically wound cellular micro fibrils made of long chain cellulose molecules [2]. These rice straw fibers are treated by soaking in an acidic and alkali solution before used in the composite. The increase in the chemical concentration of the alkali or acid damages the fiber structure. While soaking for longer time give better results due to improved crystallinity of fibers and remove of hemi cellulose and lignin. The enhancement in mechanical properties including flexural and tensile stress in alkali and acidic treated fibers is attributed to improved wetting of alkali treated with matrix. On the other hand the main function of the matrix is to bind the fibers and transfer the load to the fibers. LDPE was selected for testing procedures as it is soft, flexible and inert, thus avoid reacting with any other elements. It also has a low static charge so it does not attract dust and dirt

There are several applications for fiber reinforced plastics that are very useful these days in industry. The use of rice straw as reinforcement in polypropylene composites with $20 \%$ and $30 \%$ by weight was successfully prepared by extrusion and compression molding. The results of the mechanical properties showed that rice straw can be used as an alternative reinforcement for polypropylene. Higher tensile modulus was obtained for composites containing 
higher rice straw content. The renewability of rice straw and the recyclability of thermoplastic polypropylene provide an attractive eco-friendly quality to the resulting composites [3].

The material used for the underground pipes as shown in Figure 1 is natural fibers reinforced composite, the natural fiber used is jute or rice straw. These natural fibers are cheap with high resistance to corrosion and thermal stability. They have the advantage of avoiding contamination of water in the pipes unlike glass fibers [4].

The highway infrastructure has been deteriorating for many years, a result of harsh environmental conditions, heavy loads, and insufficient maintenance. In addition to high traffic volumes, tight construction budgets, and challenging roadway construction areas that have put a strain on the ability of conventional materials to meet the public needs for rapid construction, long lasting structural components, and lightweight, easily constructed facilities.

Fiber reinforced polymer (FRP) composite materials, which have been used for some time in the aerospace and military communities, have been perceived as a potential solution to some of the highway community's infrastructure needs because FRP's stress mesh with the shortcomings of several traditional materials. During the past decade, a significant amount of basic research has been conducted in the United States and abroad on the use of FRP composite materials for highway infrastructure applications [5]. Using polymers instead of aluminum is taken into account in the production of engine intake. They are now made from glass fiber reinforced Plastics as it is light in weight than aluminum and has improved surface quality and aerodynamics. Reduction in components by combining parts and forms into simpler molded shapes is easier in plastics than Aluminum. Pedals can be molded as single units combining both pedals and mechanical linkages simplifying the production and operation of the design [6]. FRP composites are attractive for use in civil engineering applications due to their high stress to weight and stiffness to weight ratios, corrosion resistance, light weight and potentially high durability Their application is of most importance in the renewal of constructed facilities infrastructure such as buildings, bridges, pipelines, etc. Recently, their use has increased in the rehabilitation of concrete structures, mainly due to their tailored performance characteristics, ease of application and low life cycle costs. The success of structural rehabilitation measures led to the development of new lightweight structural concepts utilizing all FRP systems or new FRP/ concrete composite systems [7]. FRP doors are produced in different lengths they have an easy workability, durable, impact resistant, water repellent, chemical resistance and stain proof. FRP roof rainwater gutters are produced to come along with support brackets in various lengths and are used in a vast array of industries. These gutters are fitted on the roof of industrial building for water drainage. FRP gratings are used in chemical, beverage, aircraft, and food applications. They have non-skid surfaces which have non corrosive nature, non-magnetic, non-conducive, and lighter than aluminum, $50 \%$ stronger than hot rolled steel, low thermal expansion as compared to aluminum and steel, low maintenance and easy installation [8].

The enhancement in mechanical properties including flexural and tensile stress in alkali treated fibers is attributed to improved wetting of alkali treated with matrix. The removal of impurities and waxy substances from fiber surface anal creation of rougher topography after alkalization thus quality of fiber will be promoted also content of hemi cellulose lignin decrease so increase effectiveness of oriented cellulose fibers. Alkali improved dispersing of fiber in matrix which resulted in increase in fiber aspect ratio this increased fiber reinforcement effectiveness. The fibers that can be treated with alkali solutions are jute, palm, wood, paper and rice straw.

A solution of $5 \% \mathrm{NaOH}$ concentration was used for two hours at $150^{\circ} \mathrm{C}$ washed with distilled water until $\mathrm{NaOH}$ was eliminated. Fibers are dried at $60^{\circ} \mathrm{C}$ for 24 hours. The increase in the chemical concentration of the alkali damages the fiber structure. When soaking for longer time give better results due to improved crystallinity of fibers and remove of hemi cellulose and lignin [9]. Another alkali treatment for sisal fibers is done by using between $4 \%$ and $10 \% \mathrm{NaOH}$ solution for $1 \mathrm{hr}$ at room temperature. The diameter, weight of fibers was found to decrease due to removal of lignin. Alkali increase the roughness of the fiber surface hence increasing the surface area available for contract for matrix. The fiber matrix adhesion increased with this treatment [10].

Adding sodium hydroxide $[\mathrm{NaOH}]$ and starch ethylene vinyl alcohol to 10 grams of rice straw improved the thermal stability of fibers, compatibility and interfacial bond stress. Tensile stress improved by $53 \%$ due to lack of impurities. Treatment in the water also improved values of Young's modulus by $75 \%$. The treatment also improved thermal degradation of fibers. These changes can be interpreted in terms of removal of hydrolyzed substances which decompose earlier than cellulose lignin leading to higher thermal stability of second step of degradation.

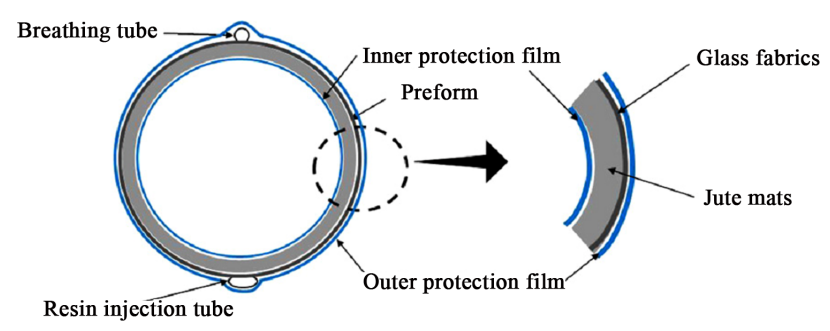

Figure 1. Reinforcement with glass fabric and jute mat [4]. 
Crystallization of fiber increases due to rupture of linkage lignin and alkali [9]. Another treatment is adding 1\% concentration of $\mathrm{NaOH}$ for $3 \mathrm{hr}$ at room temperature to rice straw, then washed and over dried at $100^{\circ} \mathrm{C}$ for $72 \mathrm{hr}$ then cleaned. The phenomenon of split fibers breaks fiber bundles into smaller ones by dissolution of hemicelluloses. This increased the effective surface area available for contact with matrix so interfacial bond improved. Pull out effect decreased in treated fibers and reduced water uptake of composite system [11].

The Coconut fiber has the same properties of rice straw. Five grams of the fiber was chemically treated by three treating agents: sodium hypochlorite $[\mathrm{NaOCl}]$, sodium hypochlorite/sodium hydroxide $[\mathrm{NaOCl} / \mathrm{NaOH}]$ or $\mathrm{Hy}-$ drogen peroxide $\left[\mathrm{H}_{2} \mathrm{O}_{2}\right]$. The effect of these treatments on the structure, composition and properties of fibers was studied using SEM. It showed that treatment with $\mathrm{H}_{2} \mathrm{O}_{2}$ is the most efficient in terms of waxy and fatty acid residues removal but it does not modify the surface chemical composition, Moreover it revealed a reduction of the hemicelluloses content in the fibers treated with $\mathrm{NaOCl} /$ $\mathrm{NaOH}$. Consequently, this fiber showed a greater exposure of cellulose and a reduction in thermal stability. This treatment was disregarded because the thermal stability is needed in several applications of FRP [12].

Another study was investigated, using four concentrations of sulphuric acid $\left[\mathrm{H}_{2} \mathrm{SO}_{4}\right](1 \%-4 \%)$ with 5 grams wheat straw at three different temperatures $\left(98^{\circ} \mathrm{C}-121^{\circ} \mathrm{C}\right.$ $\left.134^{\circ} \mathrm{C}\right)$. The predominant effect was to solubilize the hemicelluloses fraction of wheat straw. This was achieved by using the highest temperature. The solubility reached $67 \%$ but there was no significant improvement in the thermal stability and interfacial bond. But there was an improvement in tensile stress of FRP by $40 \%$ - 50\% with the concentration of $1 \% \mathrm{H}_{2} \mathrm{SO}_{4}$. This result promotes a cleaner production technique. Using $1 \%$ instead of $4 \%$ leads to reduction of chemicals at the source thus minimizing cost [13].

\section{Objective}

The objective of this paper is to investigate the potential usage of virgin polymer with rice straw as a reinforcing element to produce high value products that has technical, economical and environmental, using a simple and effective technology. Rice straw will be treated using two acids and one alkali. The mechanical properties of the composite will be investigated including flexural and tensile stress to determine the best possible mix of various parameters including length and concentration of fiber with the matrix.

\section{Design of Experiments}

Two factor data analysis of variance with three replica- tions was performed. The response with respect to tensile and flexural stress showed that the mean of virgin polymer are different. The analysis of variance test (ANOVA) showed also the different treatment methods have differrent means as shown in Table 1.

To find out which factor has the highest mean a paired comparison was performed by testing hypotheses. The proper hypotheses are the null hypothesis $\mathbf{H 0}: \beta 1=\beta 2=$ $\beta 3=0$, Ha: At least one $\beta j \neq 0$. At the significant level $\alpha$ $=0.05$, the critical value $\mathrm{t}$ is less than the observed $t$. There is a significant statistical evidence to reject the null hypothesis. It implies that at least one of the independent variables contributes significantly to the model. This test indicates that virgin polymer reinforced with natural fiber treated with phosphoric acid has a higher mean than the other natural fiber treatments. For this case a further detailed factorial design was performed.

A three factor factorial design [14] was applied to the virgin polymer reinforced with natural fiber by running design export software. The data collected for design of experiments DOE included three factors, different concentrations of natural fiber is (factor A) and the length of fiber is (factor B). The third factor $\mathrm{C}$ is the different concentration of the acid (phosphoric, sulphuric) or alkali (sodium hydroxide) that is used for chemical treatment of the natural fiber. The value of the F-statistic is at the threshold probability $\alpha$ of mistakenly rejecting a true null hypothesis. The $\mathrm{P}$ value is a probability; with a value ranging from zero to oneThe response is the effect of these factors on the mechanical properties of the composite including tensile and flexural stress. Factor A has 4 concentration levels $(0 \%, 2 \%, 5 \%$ and $6 \%)$. Factor $\mathrm{B}$ is the length of the fiber. This factor has 3 levels $(2 \mathrm{~mm}, 4 \mathrm{~mm}$ and $6 \mathrm{~mm}$ ). Factor $\mathrm{C}$ is the concentration of the acid or alkali used in treatment. This factor has two concentration levels (1\% and 5\%). Table 2 shows the different concentrations of the virgin polymer reinforced with natural fiber treated with phosphoric acid.

The P-value shown in Table 3 for each term in the model is less than 0.05 , indicating a model that is a good candidate for further exploration and validation. The variance inflation factor (VIF) was checked for the independent variables and it was found that there is no interaction between them as the value obtained for this factor

Table 1. ANOVA (two-factor with replication).

\begin{tabular}{ccccccc}
\hline ANOVA & \multicolumn{7}{c}{} & & & & \\
\hline Variation & SS & df & MS & F & P-value & F crit \\
Sample & 28.3 & 1 & 28.3 & 2321 & $4.1 \mathrm{E}-15$ & 4.74 \\
Columns & 11.6 & 2 & 5.8 & 474.8 & $3.7 \mathrm{E}-12$ & 3.88 \\
Interaction & 5.00 & 2 & 2.5 & 204.5 & $5.3 \mathrm{E}-10$ & 3.88 \\
Within & 0.14 & 12 & 0.01 & & & \\
\hline
\end{tabular}


Table 2. Data used for the three factorial design.

\begin{tabular}{cccccccccc}
\hline & \multicolumn{6}{c}{ Natural fiber concentration 4-levels (factor A) } \\
\cline { 2 - 9 } $\mathrm{m}^{2}$ & \multicolumn{2}{c}{$0 \%$} & \multicolumn{2}{c}{$2 \%$} & \multicolumn{2}{c}{$5 \%$} & $6 \%$ \\
\cline { 2 - 9 } & \multicolumn{6}{c}{ Acid concentration } & 2-levels (factor c) \\
\cline { 2 - 9 } $2 \mathrm{~mm}$ & $1 \%$ & $5 \%$ & $1 \%$ & $5 \%$ & $1 \%$ & $5 \%$ & $1 \%$ & $5 \%$ \\
\hline \multirow{6}{*}{4} & 0.9 & 0.8 & 2.9 & 2.3 & 3.2 & 2.9 & 2.8 & 2.6 \\
& 1.2 & 0.7 & 2.6 & 2.5 & 3.3 & 2.7 & 2.7 & 2.4 \\
& 0.9 & 1.1 & 2.8 & 2.3 & 3.4 & 3 & 2.8 & 2.4 \\
& 1 & 0.9 & 2.7 & 2.3 & 3.2 & 3.2 & 2.7 & 2.3 \\
& 1.1 & 1.2 & 2.6 & 2.4 & 3 & 3.1 & 2.6 & 2.5 \\
& 0.8 & 0.7 & 2.2 & 2.2 & 2.8 & 1 & 2.2 & 2.3 \\
& 0.7 & 0.6 & 2.3 & 2.3 & 2.7 & 1.2 & 2.3 & 2.2 \\
& 0.6 & 0.5 & 2.6 & 2.1 & 2.6 & 1.4 & 2.6 & 2.1 \\
\hline
\end{tabular}

Table 3. Analysis of variable parameters from design expert.

\begin{tabular}{ccccc}
\hline Source & Sum of Squares & Mean Square & F Value & P-Value \\
\hline Block & $9.9 \mathrm{E}-04$ & $4.9 \mathrm{E}-04$ & & \\
Model & 34.99 & 1.52 & 796.4 & $<0.0001$ \\
A-concentration & 28.13 & 9.38 & 4908.88 & $<0.0001$ \\
B-length & 5.14 & 2.57 & 1345.19 & $<0.0001$ \\
C-acid or alkali & $8.9 \mathrm{E}-04$ & $8.1 \mathrm{E}-04$ & 0.47 & 0.4981 \\
AB & 1.58 & 0.26 & 138.03 & $<0.0001$ \\
AC & 0.03 & 0.01 & 5.29 & 0.0032 \\
BC & $6.9 \mathrm{E}-03$ & $3.4 \mathrm{E}-03$ & 1.81 & 0.1746 \\
ABC & 0.099 & 0.017 & 8.67 & $<0.0001$ \\
Residual & 0.088 & $1.9 \mathrm{E}-03$ & & \\
Total & 35.08 & & & \\
\hline
\end{tabular}

was 1.02. The Model F-value of 796.40 implies the model is significant. Values of "Prob $>$ F" less than 0.0500 indicate model terms are significant [14].

The adjusted R-Squared is explained as the variation amount around the mean explained by the model and adjusted for the number of terms in the model (DesignExpert 2010) as shown in Table 4 i.e. when the number of terms that doesn't add up to the model increases the value of adjusted R-squared decreases. This gives a bad indicator calling for terms reduction, looking for outliers, or maybe large block effect. Therefore, higher adjusted $\mathrm{R}$-squared is desirable. The predicted R-squared is the amount of variation around the mean in the new data explained by the model. When the value of predicted Rsquared is negative; this is an indicator of having an: outlier in the data, number of runs are close to the number of model parameters. Therefore, higher predicted Rsquared is desirable. Results have shown adequate adjusted and predicted R-squared values and in two cases they are within 0.2 of each other. The "Predicted R-Squared" of 0.9939 is in reasonable agreement with the "Adjusted RSquared" of 0.9962. "Adeq Precision" measures the signal to noise ratio. A ratio greater than 4 is desirable. The ratio of 85.964 indicates an adequate signal.

The model adequacy was analyzed through tests for significance of regression and for individual regression coefficients, the first test showed that at least one of the independent variables contributes significantly to the model and the second test showed that all the independent variables contribute significantly to the response variable according to a regression equation:

$$
\mathrm{Y}=53,377-0.20868 \times 1+0.27986 \times 2-0.2685 \times 3 .
$$

where $\mathrm{Y}$ is the tensile stress in MPa, $\mathrm{x} 1$ is the virgin polymer concentration, $\mathrm{x} 2$ is the fiber length in $\mathrm{mm}$ and $\mathrm{x} 3$ is the acid concentration level.

For the data, R2 value showed $77 \%$ of the variation in response to the mechanical properties as shown in Figure 2 .

Table 4. R-squared obtained from design-expert.

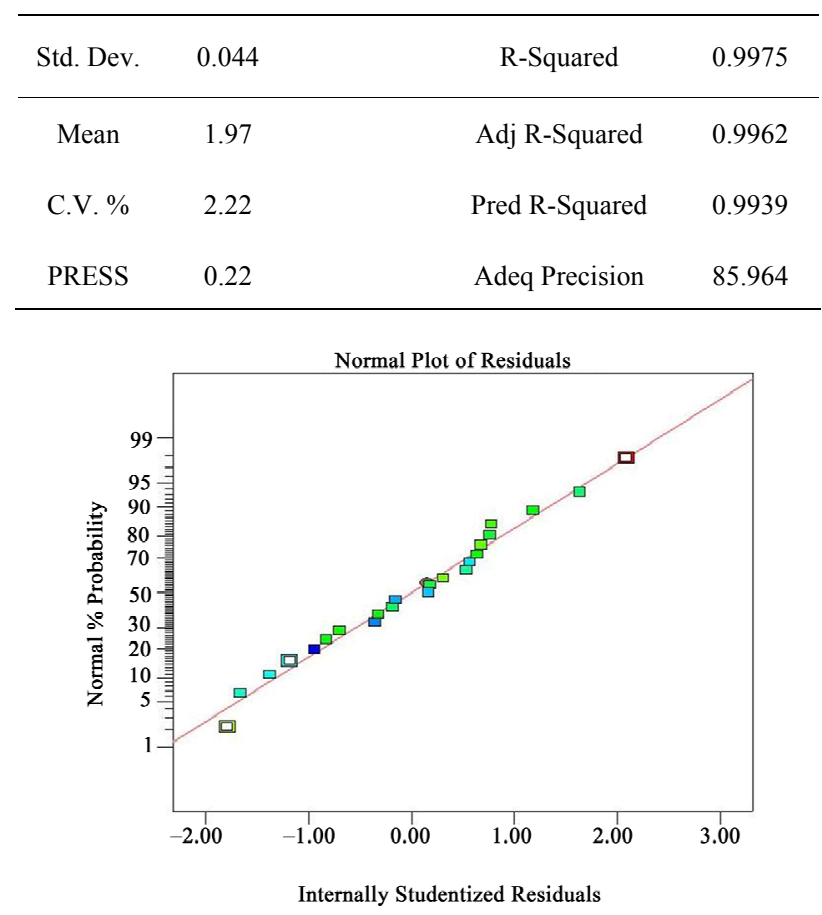

Figure 2. Normal probability plot. 
Residuals versus blocks graph in Figure 3 shows that the internally studentized residuals are not aligned in the same way i.e. each block is affecting the output in a different way. This is mainly due to different batches of plastic material causing different effects on the product. Therefore, the effect on the residuals was not consistent. However, all values fall within limits which tell a feasible output.

The response of all factors on tensile stress was investigated as shown in Figure 4. In case of studing the effect on tensile strength with phospheric acid factors A, B, $\mathrm{C}$ are significant model terms. In case of sulpuric acid, factors $\mathrm{A}, \mathrm{B}, \mathrm{C}, \mathrm{AB}$ are significant model terms. In case of soduim hydroxide: factors $\mathrm{A}, \mathrm{B}, \mathrm{C}, \mathrm{AB}, \mathrm{AC}$ are significant model terms as shown in Table 5.

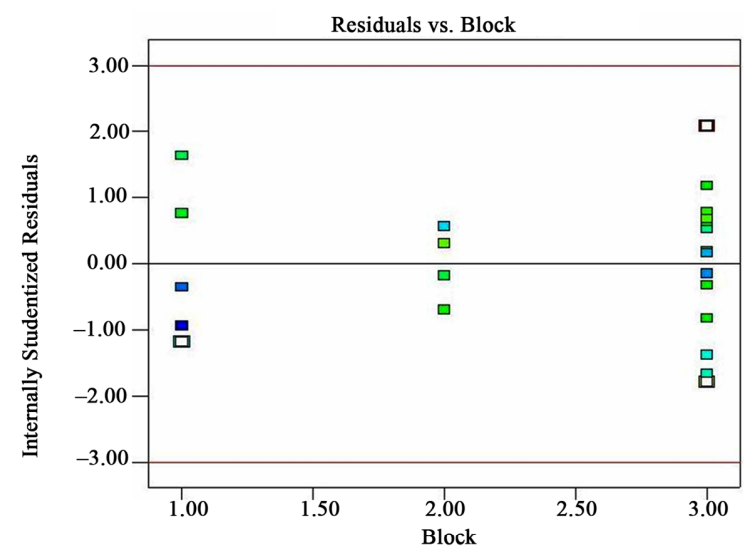

Figure 3. Residuals versus block chart.

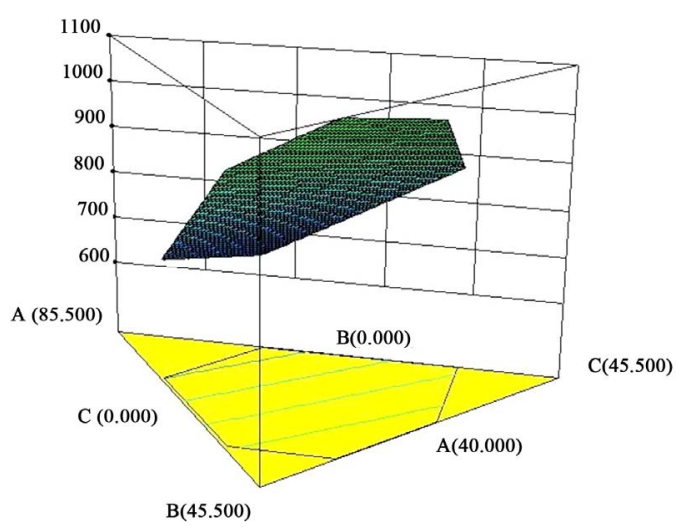

Figure 4. 3-D chart of the tensile response.

Table 5. Tensile responses from design-expert.

\begin{tabular}{cc}
\hline Tensile stress & Significant factors \\
\hline Phospheric acid $^{*}$ & A, B, C \\
Sulphuric acid & A, B, C, AB \\
Soduim hydroxide & A, B, C, AB, AC \\
\hline
\end{tabular}

${ }^{*}$ This is the case that was studied in details.

\section{Experimental Procedure}

Rice straw fibers were cut to three lengths $(2 \mathrm{~mm}, 4 \mathrm{~mm}$ and $6 \mathrm{~mm}$ ) through a shredder. The fibers were treated with $1 \%$ and $5 \%$ phosphoric acid, sulphuric acid and sodium hydroxide. The scale used to weigh the fibers was calibrated using linear regression method based on standard weights brought from the polymers lab at the American University in Cairo. The fiber was soaked for 2 hours at $150^{\circ} \mathrm{C}$ in the acid and alkali solutions then washed with distilled water. The treated fiber is dried in a furnace at $60^{\circ} \mathrm{C}$. It was assured that the moisture was totally eliminated. The fibers were weighed every hour. After 8 hours, the weight did not change assuring that the fibers are dry. This procedure was repeated 3 times to guarantee the results. The fibers and polymer were mixed using a mixer then the mix is fed into the single screw extruder. Processing was carried out using the extrusion machine. The process started by placing the mix of polymer and treated fiber in the hopper of the extrusion machine. Temperatures were set at $120^{\circ} \mathrm{C}$ for the first heater and $150^{\circ} \mathrm{C}$ for the second heater in the extruder. The first heater used to heat the mix to a desired temperature and properly melt it while the second heater ensured the flow of melted plastic with the additives before extrusion of the paste from the die. The heaters are insulated and covered with glass wool to contain heat and minimize heat loss. The cooling section is located at the beginning of the extruder with the water inlet and outlet to guarantee there is no melting in the mixing or feeding chamber. The mix was placed slowly so as not to clog up the rotating screw that allows input into the machine. The resulted extrudates were obtained within 17 minutes for 500 grams. The paste was taken to a hydraulic press to be pressed. A custom made steel die with specific dimensions is used to satisfy the requirements of testing. Trimming and cutting processes are done to make the product ready for testing in accordance with the requirements of the testing standards. Mechanical testing of these chemically treated natural fibers includes tensile test and flexural test are the performed tests in this research. The standard specimens are tested at a rate of $(2 \mathrm{~mm} / \mathrm{min}$ $5 \mathrm{~mm} / \mathrm{min}$ ). The flexural stress, failure strain and tensile stress can be calculated from stress strain curve. Sample standard dimensions according to ASTM are (40 - 100 $\mathrm{mm})$ length $(10-20 \mathrm{~mm})$ width and $(2-5 \mathrm{~mm})$ thickness [15].

\section{Results}

\subsection{Effect of Fiber Reinforcement on LDPE Using Flexural Test}

Three samples for each treatment condition were tested in accordance with ASTM D 790-03 to determine the 
flexural stress of FRP of $2 \%$ and $5 \%$ rice straw of length $2 \mathrm{~mm}$ treated with sodium hydroxide alkali. The increase in fiber content showed an improvement in flexural stress at $5 \%$ fiber concentration. The $5 \%$ concentration of the alkali showed a slight change in flexural stress than $1 \%$ as shown in Figure 5. From this micro analysis it is clear that interfacial stress between the rice straw and LDPE matrix is the most indispensable factor for achieving good fiber reinforcement. The interface acts as a "binder" and transfers the load between the matrix and the reinforcing fibers. Mechanical stress of the composites levels decrease at high fiber loading. This behavior can be explained on the basis that at higher fiber loading the fiber-fiber contact dominates over the resin matrix-fiber contact, which decreases the mechanical properties. The same procedure for sodium hydroxide treatment is done using sulphuric acid treatment for each condition. The increase in fiber concentration from $2 \%$ to $5 \%$ showed an improvement in flexural stress. The concentration of the acid showed no significant change in flexural behavior as shown in Figure 6. The same procedure for previous treatment is done using phosphoric acid with several samples repeated for each condition. The increase in fiber concentration from $2 \%$ and $5 \%$ showed an improvement in flexural stress. The different concentration of the acid showed slight change in flexural behavior as shown in Figure 7. The flexural stress values of $\mathrm{NaOH}$ treated fiber and the $\mathrm{H}_{3} \mathrm{PO}_{4}$ treated fibers have higher flexural behavior than the $\mathrm{H}_{2} \mathrm{SO}_{4}$ treated fibers. It can be concluded that the most suitable treatment is the one with the $\mathrm{H}_{3} \mathrm{PO}_{4}$ acid with $5 \%$ fiber content and $1 \%$ fiber concentration. The effect of $5 \%$ of treated fiber concentration using $1 \%$ chemical concentration with 2, 4 and $6 \mathrm{~mm}$ fiber length on the reinforcement of LDPE was investigated. Flexural stresses were decreased for composites with 4 and $6 \mathrm{~mm}$ length compared to the $2 \mathrm{~mm}$ fiber reinforced composites as shown in Figure 8.

\subsection{Effect of Fiber Reinforcement on LDPE Using Tensile Test}

Three samples were tested for each condition in accordance with ASTM D 3039 to determine the tensile stress of FRP of $2 \%$ and $5 \%$ rice straw of length $2 \mathrm{~mm}$ treated with sodium hydroxide alkali. The increase in fiber content showed an improvement in tensile stress at 5\% fiber. Samples of $1 \%$ and $5 \%$ concentration of $\mathrm{NaOH}$ were also tested. The 5\% concentration of the alkali showed no significant change in tensile stress than $1 \%$ as shown in Figure 9. Three samples for each condition were tested in accordance with ASTM D 3039 to determine the tensile stress of FRP of $2 \%$ and $5 \%$ rice straw of length 2 $\mathrm{mm}$ with sulphuric acid treatment. The increase in fiber content showed an improvement in tensile stress at $5 \%$.

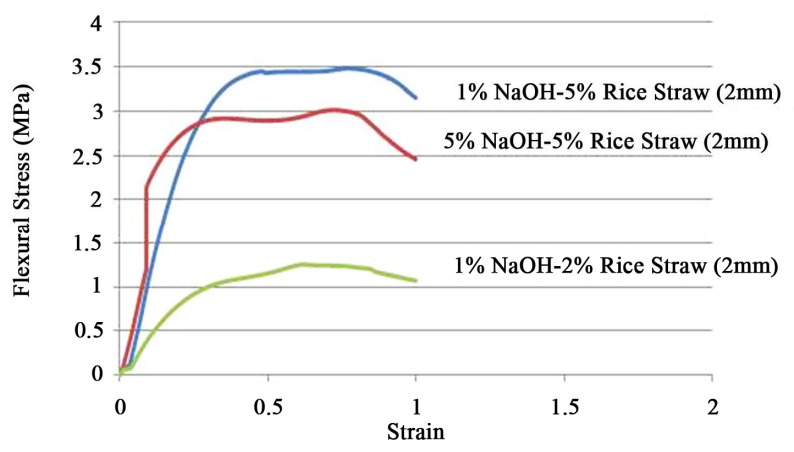

Figure 5. Variation of flexural stress for different fiber conc. with $2 \mathrm{~mm}$ length using $1 \%$ and $5 \% \mathrm{NaOH}$.

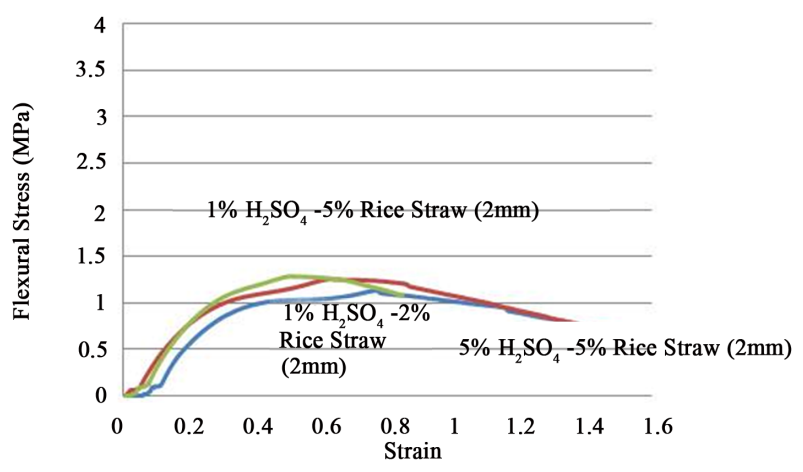

Figure 6. Variation of flexural stress for different fiber conc. with $2 \mathrm{~mm}$ length using $1 \%$ and $5 \% \mathrm{H}_{2} \mathrm{SO}_{4}$.

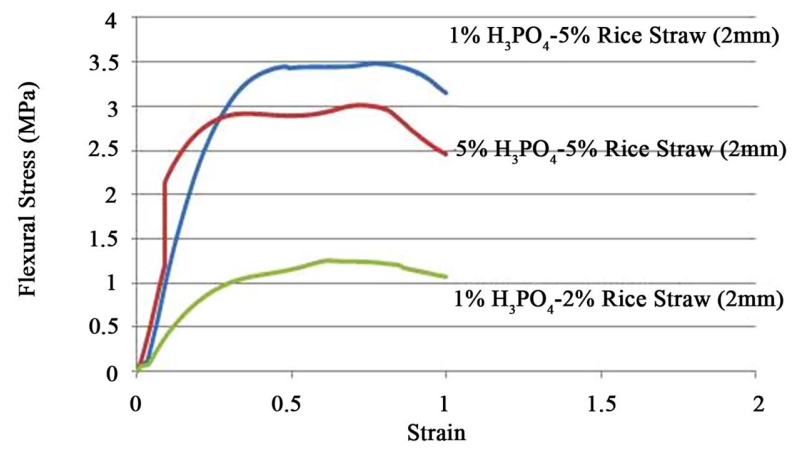

Figure 7. Variation of flexural stress for different conc. of fiber with $2 \mathrm{~mm}$ length using $1 \%$ and $5 \% \mathrm{H}_{3} \mathrm{PO}_{4}$.

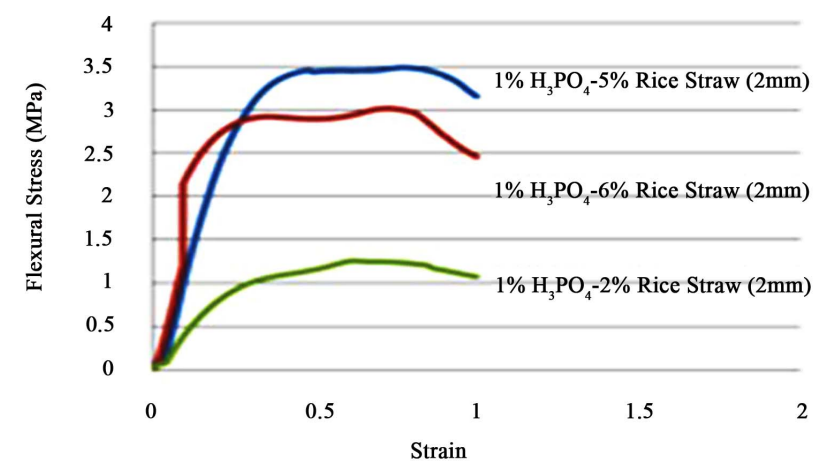

Figure 8. Effect of fiber length on flexural stress using $1 \%$ chemical conc. \& $5 \%$ fiber conc. 


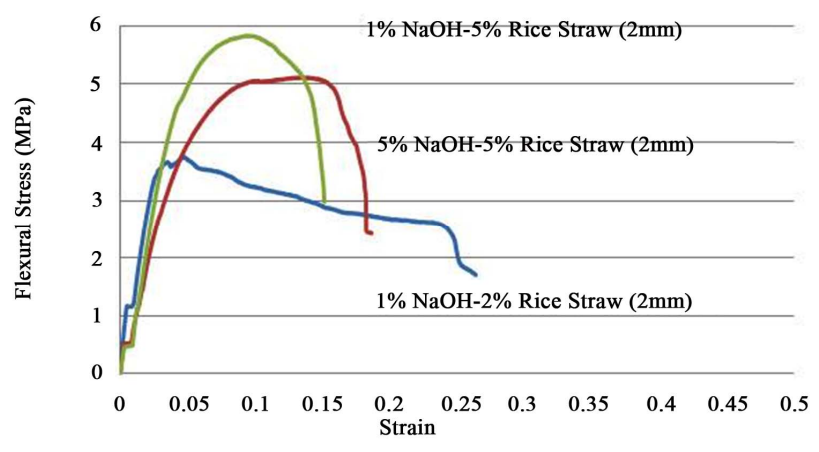

Figure 9. Variation of tensile stress for different fiber conc. with $2 \mathrm{~mm}$ length using $1 \%$ and $5 \% \mathrm{NaOH}$.

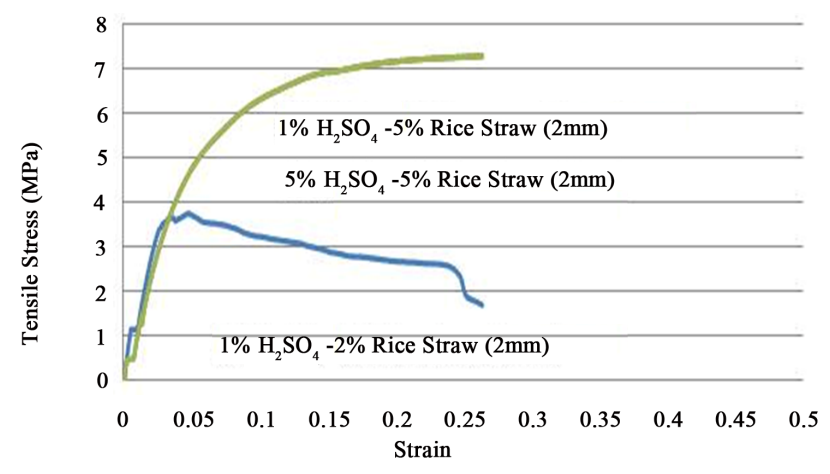

Figure 10. Variation of tensile stress for different fiber conc. with $2 \mathrm{~mm}$ length using $1 \%$ and $5 \% \mathrm{H}_{2} \mathrm{SO}_{4}$.

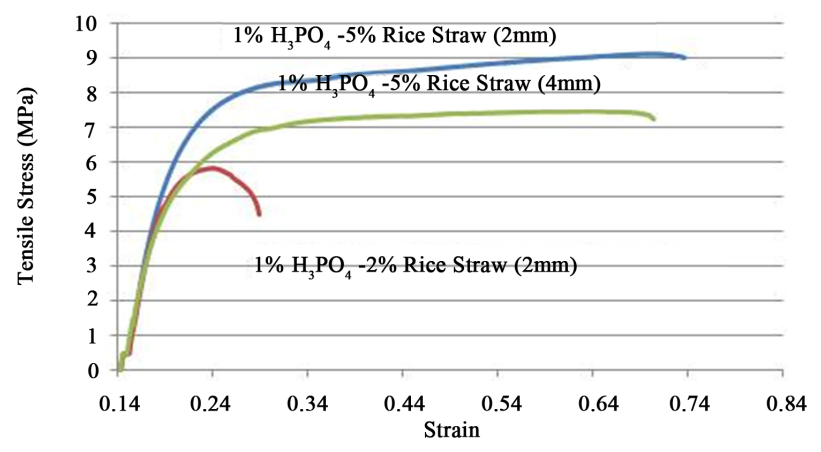

Figure 11. Variation of tensile stress for different conc. of fiber with $2 \mathrm{~mm}$ length using $1 \%$ and $5 \% \mathrm{H}_{3} \mathrm{PO}_{4}$.

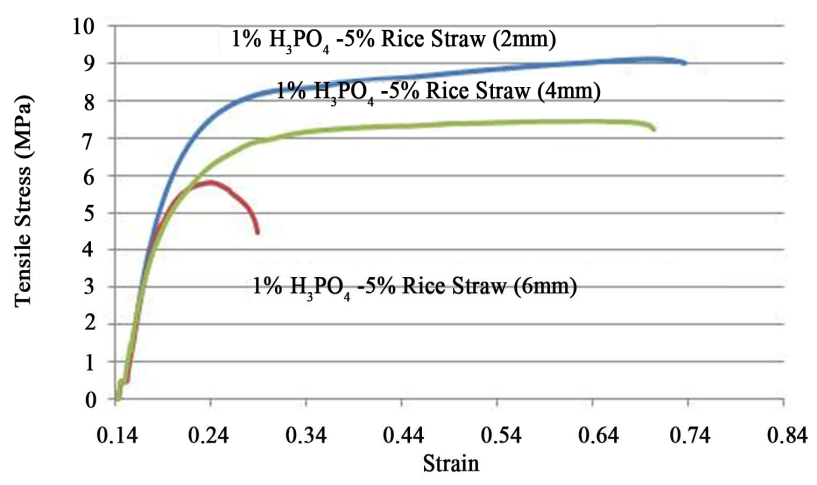

Figure 12. Effect of fiber length on tensile stress using $1 \%$ chemical conc. \& $5 \%$ rice straw.
The $5 \%$ and $1 \%$ concentration of the acid showed no significant change in tensile stress as shown in Figure 10. Three samples were tested in accordance with ASTM D 3039 to determine the tensile stress of FRP of $2 \%$ and $5 \%$ rice straw of length $2 \mathrm{~mm}$ with phosphoric acid treatment. The increase in fiber content showed an improvement in tensile stress at 5\% fiber. The 5\% concentration of the acid showed no significant change in tensile stress than 1\% as shown in Figure 11.

It is concluded that phosphoric acid treatment has the highest tensile stress compared to the other acid and alkali. The effect of 5\% of treated fiber concentration using $1 \%$ chemical concentration with 2,4 and $6 \mathrm{~mm}$ fiber length on the reinforcement of LDPE is investigated. Tensile stress for composites of fiber length 4 and $6 \mathrm{~mm}$ decreased, compared to $2 \mathrm{~mm}$ fiber reinforced composites as shown in Figure 12.

\section{Conclusion}

Several chemical treatments (phosphoric acid, sulphuric acid and sodium hydroxide) of natural fibers are used for polymer composites using acids and alkali were tested. The most suitable chemical was the phosphoric acid with $1 \%$ chemical concentration due to obtaining the highest values of tensile and flexural stress compared to the other treatments. Moreover, the waste generated from the chemical treatment of rice straw using phosphoric acid can be utilized as a fertilizer component for land reclamation. The fiber concentration of rice straw used was $5 \%$ as it showed improvement in flexural and tensile stress. This percentage was recommended through literature review. Increasing the fiber concentration to $6 \%$ in the experimentation stage lowered the flexural stress 2 times and the tensile stress 4 times. Increasing the fiber length to 4 and $6 \mathrm{~mm}$ length reflected lower flexural and tensile stresses. The improper bonding occurs between the fibers and the matrix due to increase in fiber length causing aggomeration and fiber clamping. Fiber entanglement also contributes in stress reduction.

\section{REFERENCES}

[1] P. Wambua, J. Ivens and I. Verpoest, "Natural Fibres: Can They Replace Glass in Fiber Reinforced Plastics," Department of Metallurgy and Materials Engineering, Belgium, 2007.

[2] K. Pickering, "Properties and Performance of NaturalFiber Composites," University of Waikato, Waikato, 2008.

[3] A. Grozdanova, A. Buzarovskaa, G. Bogoeva-Gacevaa, M. Avellab, M. E. Erricob and G. Gentilleb, "Rice Straw as an Alternative Reinforcement in Polypropylene Composites," Argonmy for Sustainable Development, Vol. 26, 2006. 
[4] H. Seong and S. Kim, "Application of Natural Fiber Reinforced Composites to Trenchless Rehabilitation of Underground Pipes," Department of Mechanical Engineering, Korea Advanced Institute of Science and Technology, 2008.

[5] http://www.quakewrap.com/frp

[6] R. Kikuchi, J. Kukacka and R. Raschmn, "Grouping of Mixed Waste Plastics according to Chlorine Content, Separation and Purification Technology 61, No.1 (2008): 75-81 Lelli V., Zhao, L. and Seible, F.," Use of FRP Composites in Civil Structural Applications, Elsevier, Vol. 17, 2003, pp. 389-403.

[7] V. Lelli, L. Zhao and F. Seible, "Use of FRP Composites in Civil Structural Department of Structural Engineering," University of California, 2003.

[8] http://www.tradeindia.com/manufacturers/indianmanufact urers/frp-products.html

[9] B. Bachtiar, S. Sapuan and M. Hamdan, "The Effect of Alkaline Treatment on Tensile Properties of Sugar Palm Fibre Reinforced Epoxy Composites," Department of Me- chanical and Manufacturing Engineering, Malaysia, 2007.

[10] J. Maya and T. Sabu, "Mechanical Properties of Sisal/Oil Palm Hybrid Fiber Reinforced Natural Rubber Composites," School of Chemical Sciences, Mahatma Gandhi University, 2004.

[11] M. Haque and M. Hasan, "Physico Mechanical Properties of Chemically Treated Palm and Coir Fiber Reinforced Polypropylene," National University, Bangladesh, 2009.

[12] A. Brígida, A. Calado and M. Coelho, "Effect of Chemical Treatments on Properties of Green Coconut Fiber," BioResources, Vol. 79, 2010, pp. 832-838.

[13] S. Baek and Y. Kwon, "Optimization of the Pretreatment of Rice Straw Hemicellulosic Hydrolyzates for Microbial Production of Xylitol Biotechnology and Bioprocess," Engineering, Vol. 12, No. 4, 2007, pp. 404-409.

[14] Montgomery and C. Douglas, "Design and Analysis of Experiments," 5th Edition, John Wiley, New York, 1999.

[15] ASTM: Standard Guide for Testing Polymer Matrix Composite Materials. ASTM Standards Source, Philadelphia. 